\title{
SUBSTANCES FOR USE IN THE DIAGNOSIS AND TREATMENT OF VASCULAR DISEASE
}

\author{
By J. H. BurN, M.D., F.R.S. \\ Professor of Pharmacology, Oxford University
}

\section{The Control of Vascular Tone}

During the last few years there has been a steady increase in the number of substances which have been used clinically in the diagnosis of vascular disease and also to some extent in its treatment. These fall into three groups. There are ganglionblocking agents such as tetraethylammonium salts, there are sympatholytic agents, and finally a group not sharply separated from these, the adrenolytic agents. All have the effect of reducing vascular tone, though their mode of action is not the same.

To understand the differences between them, it is useful to consider the diagram in Fig. 1 , which shows Gaskell's conception (I916) of the.difference between the ordinary reflex arc and the sympathetic reflex arc. Gaskell considered that every segment of the cord contained arcs each consisting of three neurones (I) a sensory neurone terminating around the cell of (2) a connector

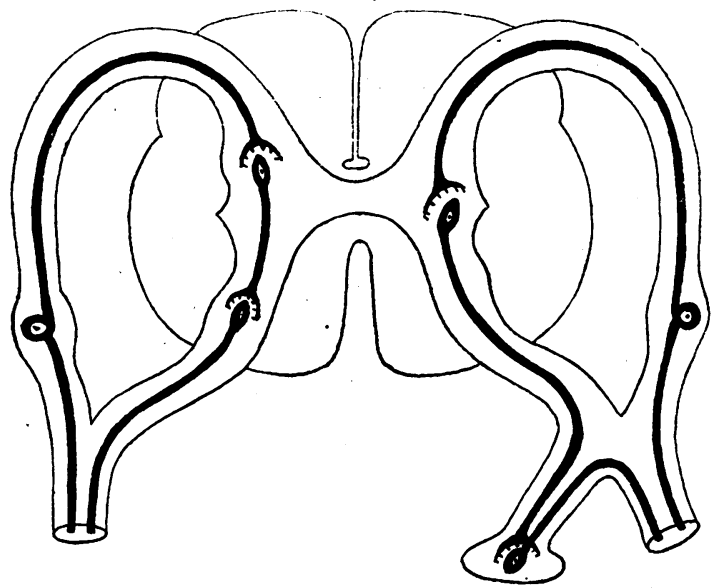

FIG. 1.-Taken from a drawing by W. H. Gaskell. On the left is shown the fibres of the reflex arc for voluntary muscles. Between the sensory and motor fibres is a connector fibre. On the right is the arrangement in the sympathetic reflex arc. The connector fibre runs to the sympathetic ganglion as a white ramus. The cell of the postganglionic fibre thus corresponds to the anterior horn cell of the voluntary reflex arc. neurone, in turn terminating around (3) a motor neurone. Motor neurones passing to skeletal muscle of course begin in anterior horn cells as shown on the left-hand side of Fig. I. Gaskell supposed that in addition to these reflex arcs belonging to the voluntary system of muscles there were reflex arcs belonging to the involuntary or autonomic system, of which those supplying the blood vessels were part of the sympathetic system. In these arcs the connector fibre began in the lateral horn and instead of terminating within the cord continued along the motor root until this joined the sensory root; it then left the mixed motor and sensory nerve to pass as a white ramus communicans to a sympathetic ganglion. Here it terminated around the cell of a postganglionic motor neurone, which travelled as a grey (nonmedullated) ramus back to the mixed nerve and then onwards to a blood vessel in the periphery. This course is shown on the right-hand of Fig. I. The sympathetic ganglion, according to this scheme, corresponds to the junction between the connector fibre and the motor fibre in the grey matter of the anterior horn; the sympathetic ganglion, however, having a blood supply of its own, is much more accessible to drugs.

The sympathetic chains on each side of the spinal cord, thus consist of ganglia like that shown in Fig. I, joined to each other by fibres running parallel to the spinal cord. Any preganglionic fibre leaving the cord may not terminate in the first sympathetic ganglion it reaches; it may travel upwards or downwards in the sympathetic chain to another ganglion. Similarly the postganglionic fibres starting in any ganglion may not at once pass as a grey ramus to the mixed nerve of its own segment ; it may pass in the sympathetic chain to another ganglion before turning to the periphery. Moreover, many of the fibres terminating around the cells of postganglionic neurones in sympathetic ganglia take origin in the vasomotor centre of the medulla and in subsidiary centres which may exist in the cord. These vasomotor centres send impulses along the pre- 
ganglionic fibres, which are transmitted to postganglionic fibres at the numerous ganglionic synapses, and thus maintain vascular tone.

A word should be said about the conception of subsidiary vasomotor centres in the spinal cord. When the medulla is destroyed, respiration stops at once because the respiratory centre is destroyed. Thus it is impossible to suppose that subsidiary respiratory centres exist. When the medulla is destroyed, the blood pressure usually falls slowly, not at once, and occasionally it remains high for some hours. If the spinal cord, however, is destroyed the blood pressure falls to a very low value immediately. These observations have been interpreted to mean that there are subsidiary vasomotor centres in the cord. They can equally well mean that just as the tone of skeletal muscle depends on proprioceptive impulses arising in sense organs placed in the tendons of the muscles and preceding through the cord in a reflex arc, so the tone of blood vessels may depend on similar proprioceptive impulses; if the spinal cord is destroyed, a reflex which follows the path shown either on the left or the right side of Fig. I will be arrested and tone will disappear.

\section{Tetraethylammonium and Ganglion Block}

Excessive vascular tone may then be nervous in origin, due to too great a stream of vasoconstrictor impulses from the vasomotor centre or else to too great a degree of reflex tone. The excess of vascular tone can be removed, temporarily at least, by agents which impede transmission in the sympathetic ganglia. Another possibility is that excessive vascular tone is due to the vessels themselves, which because of some change in their metabolism, or because of some abnormal constituent in the blood are more than usually constricted. In this case also the tone can be reduced by diminishing the nervous impulses which reach the vessels.

Nicotine has long been known to stimulate the sympathetic ganglia in small doses, and to paralyse them in large doses. In I9I5 Burn and Dale examined the action of tetramethylammonium and tetraethylammonium salts ; they found that when these substances were administered to atropinized cats the former exerted an action in all respects similar to that of nicotine, and the latter exerted a part of this action, that is to say, it caused ganglionic depression. The idea of making clinical use of this property did not arise until 30 years later when two American pharmacologists, Acheson and Moe (I945), re-investigated the action of tetraethylammonium salts and published full evidence of the blocking action in various ganglia, together with the finding that these salts have a beneficial effect on the failing heart. These workers then obtained the collaboration of clinical

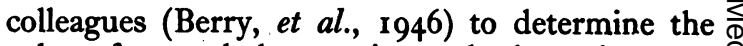
value of tetraethylammonium salts in patients, as $\stackrel{\varrho}{c}$ compared with that of existing methods of diminishing peripheral vascular tone, namely, $\stackrel{\vec{s}}{\rightarrow}$ lumbar sympathetic block, spinal anaesthesia, local o nerve block and sympathectomy. They ad- 음 ministered the bromide as a 10 per cent. solution $\frac{\bar{m}}{\bar{D}}$ to 500 patients either by intravenous or intra- $\overparen{\otimes}$ muscular injection giving amounts from 0.2-0.5 g. ฏ intravenously, and up to $20 \mathrm{mg} . / \mathrm{kg}$. intra- क muscularly. The effect of intramuscular injection $\vec{\circ}$ lasted from six to eight hours, though this varied a good deal.

\section{Glinical Effects}

Patients with vascular spasm such as Raynaud's i disease responded by a rise in the skin tempera- in ture, and by a change from cyanosis to a red $\stackrel{\infty}{\longrightarrow}$ colour; daily injections produced a gradual $\vec{\circ}$ abatement of Raynaud's syndrome with relief of 을 pain. Similarly patients with thromboangitis obliterans; and intermittent claudication were im- proved. Numbness and tingling in the leg and $\vec{z}$ nocturnal pain in the foot disappeared. That the rise of skin temperature was due to increased blood flow was shown by Slaughter, Brown and Wakig $\vec{\emptyset}$ (1948). In the experiments in which other pros 0 cedures were compared with the injection of tetraethylammonium bromide in the same patients, it was found that in 52 out of 55 , the injection of tetraethylammonium bromide was equal or superior to other methods of producing block, and of course much easier to apply.

A review of the use of the drug has been published by Lyons, Moe, et al. (1947) in which they state that, apart from the vascular action, it produces a cessation of normal peristalsis in the gastro-intestinal tract, and a diminution in gastric secretion. In considering its action they emphasize that its chief use is diagnostic, being helpful in selecting patients for sympathectomy; unless the administration of the tetraethylammonium salt is attended by a fall in blood pressure, $\bigcirc$ the operation of sympathectomy will not reduce the blood pressure. Thus a failure to observe a fall of blood pressure after giving tetraethylammonium excludes sympathectomy. Unfortunately the converse does not apply, for many patients in $N$ whom the drug does cause a fall of blood pressure are not improved by sympathectomy (Birchall, Taylor, et al., 1947).

Tetraethylammonium salts when given in ex- $\frac{\mathscr{C}}{\mathbb{D}}$ cessive dose produce unwanted effects which $\stackrel{\oplus}{?}$ include dilatation of the pupil, numbness in the 0 periphery, tingling and ptosis of the eyelids. Next are dryness of the mouth, vascular weakness and 
nasal congestion. Finally, curare-like effects lead to dysarthria, dysphagia and intercostal paralysis. No fatalities have been recorded; adrenaline has been found a useful antidote for too great a fall in blood pressure, while muscular weakness is overcome by giving prostigmine together with atropine.

\section{Adrenolytic and Sympatholytic Substances}

The discovery by Dale (1906) of a substance in ergot which reduced and also reversed the pressor action of adrenaline is now widely known. The substance was isolated as ergotoxine ; later (1920) Stoll isolated ergotamine, another substance in ergot with the same properties. Other plant alkaloids, yohimbine and corynanthine were described by Raymond Hamet (1925-7), and then came synthetic substances (Gravitol, introduced by Fichholz (1928); Tastromine, introduced by Anan and Okazaki (1930-2)) which were in turn overshadowed by two compounds prepared in Paris by Fourneau and Bovet (1933) known as $88{ }_{3} \mathrm{~F}$ and $933 \mathrm{~F}$. Another compound, priscol, was investigated by Hartmann and Isler (1939) and recently Nickerson and Goodman (I947) have introduced dibenamine. The formulae of the Fourneau compounds, and of priscol and dibenamine, are given in Fig. 2.

These substances all reduce the action of adrenaline, and to some extent the effect of sympathetic stimulation also, though this varies from one substance to another. It is probable that they exert their effect because they possess adrenaline-like properties which enable them to compete for the cell-receptors to which adrenaline attaches itself in order to act. Thus they block the way for adrenaline molecules and these then have no effect. But because their action depends on a resemblance to adrenaline they produce effects when administered like those of adrenaline. The patient may be conscious of increased rate and force of heart beat and complain of palpitations, and he may feel frightened.

The compounds under consideration thus differ from tetraethylammonium salts in their site of action. They do not act, like tetraethylammonium, on the sympathetic ganglion, but they act on the blood vessel wall to make it insensitive to adrenaline or even to sympathetic stimulation. Their sphere of usefulness is two fold. They can be used for the diagnosis and treatment of vascular spasm in much the same way as tetraethylammonium salts. The compound with the most prolonged action is dibenamine and Nickerson and Goodman say that in man after a single injection a fall of blood pressure of gradual onset is obtained which lasts from about 36 hours to five days. No full reports of clinical trials have yet

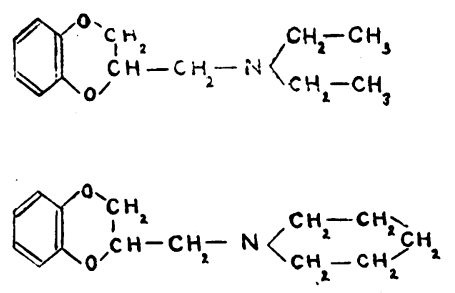

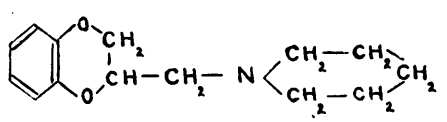

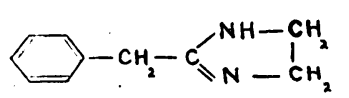

PrISCOL

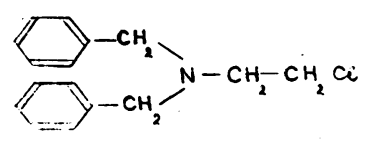

Dibenamine

\section{Fig. 2.}

been published and, for the present, judgment about the use of dibenamine in Raynaud's disease, early Buerger's disease, causalgia and the vascular spasm accompanying embolism and thrombophlebitis must be suspended.

\section{Diagnosis of Adrenal-Medullary Tumours}

There is, however, another use of these com- 8 pounds, to which $933 \mathrm{~F}$ has been chiefly applied, namely, for the diagnosis of conditions in which adrenaline or an adrenaline-like substance is $\rightleftharpoons$ present in the blood. The one recognized clinical condition is produced by the presence of an adrenal-medullary tumour, known as a phaeochromocytoma. This contains large amounts of adrenaline which escapes from time to time into the circulation and produces the same symptoms as those which follow the intravenous injection of 0.5-1.0 mg. adrenaline. A recent tumour examined in my laboratory by Mrs. Holton was found to contain $3.4 \mathrm{mg}$. of adrenaline and 6.7 mg. of nor-adrenaline per $\mathrm{g}$. tumour. It has till recently been believed that these tumours always release adrenaline intermittently thus giving rise to crises of high blood pressure, between which the blood pressure is normal. Cases are now known in which the rise of blood pressure has been persistent, and the diagnosis of an adrenalmedullary tumour is therefore compatible with a persistent high pressure. If there are no intermittent crises the diagnosis is difficult; it is assisted by intravenous pyelography, and also by perirenal pneumograms.

Goldenberg, Snyder and Aranow (1947) now describe a new test for this form of hypertension. The patient is given an intravenous drip of saline, and into it is slowly injected, taking not less than 2 min., about $15 \mathrm{mg}$. of $\mathrm{F}_{933}$ dissolved in $1.5 \mathrm{cc}$. 
If the high blood pressure is due to excess of adrenaline, there is a rapid fall in systolic pressure of about $60 \mathrm{~mm}$., which then returns to its initial value in $20-40 \mathrm{~min}$. If the hypertension is renal in crigin, there is no fall, and indeed there is sometimes a slight rise. By this test the presence of a phaeochromocytoma can be diagnosed, and its complete removal ensured. Ganem and Cahill (1948) quote a patient in whom such a tumour was removed. Eight weeks later, although the blood pressure was lower, it was still high, and a test of the kind described using a related substance, $F_{1164}$, caused a drop from $160 / 144$ to $100 / 60$. A second operation was undertaken and a further tumour discovered. The removal of this was followed by uneventful recovery and the blood pressure fell to II $/ 54$. There seems to be no important difference between $\mathrm{F}_{933}$ and $\mathrm{F}_{11} 6_{4}$ in clinical use. Both must be given slowly as there may be tachycardia, flushing and a feeling of fright. Disturbing side actions do not often last longer than $3 \mathrm{~min}$. and are rare with the slow injection.

The fact that hypertension due to an adrenalmedullary tumour can be completely removed by operation makes it important to use all possible means to discover whether such a tumour is present. This simple test should therefore not be neglected.

\section{Formation of Pressor Amines}

While considering conditions in which pressor amines like adrenaline and noradrenaline may. be found in the blood, recent work on the enzymes which convert amino acids into amines should be given attention. There exists an enzyme in the kidney capable of removing the $-\mathrm{COOH}$ group from dihydroxylphenylalanine ('dopa') and thereby converting it into an amine which causes the blood pressure to rise. This enzyme was demonstrated in different tissues by Holtz and Heise (1938). Bing (194I) injected dopa into the perfused kidneys of the cat and showed that in conditions of oxygen lack a substance which raised the blood pressure was formed. Bing and Zucker (I94I) put clamps temporarily on the renal vessels of an anaesthetized cat ; they injected dopa into one kidney. When they removed the clamps after two hours from the uninjected kidney, no rise of blood pressure occurred; but when the clamps were removed from the injected kidney, there was a rise of about $100 \mathrm{~mm}$., indicating that a pressor amine, probably hydroxytyramine had been formed. Next Holtz and Credner (1942) made the observation that when dopa was given by intravenous injection or by mouth to rabbits, a pressor substance appeared in the urine which they were able to identify chemically as hydroxytyramine. Thus they showed that this process of amine formation took place normally in the body due to the activity of the dopa decarboxylase.

In the course of further work, Holtz, Credner $\frac{3}{\infty}$ and Kroneberg (1947) have shown that in normal $\varrho$ human urine there are pressor substances which $\stackrel{\complement}{\hookrightarrow}$ are set free after acid hydrolysis, and they have $\overrightarrow{\vec{\rho}}$ produced pharmacological evidence which strongly $\overrightarrow{0}$ suggests that these are a mixture of hydroxytyr- $\frac{\bar{O}}{\sigma}$ amine, noradrenaline and adrenaline. They think $\frac{\bar{\sigma}}{\overline{0}}$ that these substances may be produced in excess in $\widehat{D}$ the process of adrenaline formation, and that the body then gets rid of the excess by combining it $\infty$ into inactive forms which are excreted in the urine. $\overrightarrow{0}$ They call the mixture urosympathin. They find $\overrightarrow{\vec{\omega}}$ that the amount of these substances in the urine is $\stackrel{\sigma}{\omega}$ increased in healthy individuals after strenuous $\overrightarrow{8}$ exercise, and that the amount is also increased in 3 patients suffering from essential hypertension. In N normal individuals the amount of urosympathin in excreted in 24 hours is equivalent to $2-3 \mathrm{mg}$. $\stackrel{\infty}{\rightarrow}$ hydroxytyramine, or to $0 . \mathrm{I}-0.15 \mathrm{mg}$. adrenaline. In essential hypertension it is equivalent to $8 \mathrm{mg}$. 오 hydroxytyramine.

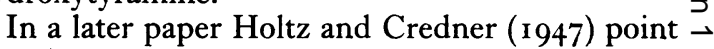
out that renal ischaemia, by reducing the oxygen 3 supply, will inactivate another enzyme which probably plays a part in removing substances like $\supset$ hydroxytyramine which may be formed in exces\& $\overrightarrow{0}$ This is the enzyme amine oxidase which convers hydroxytyramine to dihydroxyphenylacetaldehydō. The inactivation of amine oxidase will raise the amount of pressor amines in the blood.

A further factor which may raise the amount of pressor amines in the blood is loss of excretory power. Holtz and Credner administered $50 \mathrm{mg}$. L-dopa intravenously to I 4 patients with nephritis and high blood pressure and also to eight healthy subjects; they tested the urine secreted in the following two to four hours for the presence of hydroxytyramine on the blood pressure of the cat. $\frac{3}{3}$ They found little or no hydroxytyramine in the urine of the patients with nephritis and high blood 3 . pressure, but considerable amounts in that of the $\delta$ normal subjects. They demonstrated that the absence of hydroxytyramine in the patients' urine 0 was not due to failure to convert the dopa to hydroxytyramine, for they found no dopa in the urine when they tested it for the total amount of polyphenol compounds. Thus renal ischaemia os may lead to over-production of pressor amines, $N$ and by inactivation of amine oxidase to their $\underset{\mathrm{N}}{\mathrm{J}}$ retention in the blood.

Thus hypertension of renal origin may be due to two different factors. Principally, it is due to the action of renin on hypertensinogen liberating $\stackrel{0}{?}$ hypertensin in the blood. A subsidiary factor is 0 the formation of these pressor amines. The only evidence we have of them at present is the evidence 
that the urine of persons with essential hypertension yields larger amounts than normal or urosympathin on acid hydrolysis.

\section{BIBLIOGRAPHY}

ACHESON, G. H., and MOE, G. K. (1945), .7. Pharmacol. Exp. Ther., $84,189$.

ACHESON. G. H., and MOE, G. K. (1946), Ibid., 87, 220.

ANAN, S. (1930), fap. F. Med. Sci., Trans. IV. Pharmacol. 4, 70 BERRY, R. L., CAMPBELL, K. N., LYONS, R. H., MOE, G. K., and SURTTER, M: R. (1946), Surgery, 20, 525.

BING, R. J. (1941) Amer. F. Physiol.,.132, 497.

BING, R. J., and ZUCKER, M. B. (I94I), Ibid., 133 , 214

BIRCHALL, R., TAYLOR, R. D., et al. (1947), Amer. .1. Med. $S c i ., 213,572$.

BLRN. J. H., and DALE, H. H. (1915), f. Pharmacol. Exp. Ther. 6,417 .

DALE, H. H. (1906), \%. Physiol., 34, 163.

EICHHOLZ, F. (1928), Munch. med. Woch., 75, 1281.

FOURNEAU, E., and BOVET, D. (1933), Arch. internat. Pharmacodyn. et Therap., 46, i 78 .

GANEM, E. J., and CAHIL̈L, G. F. (1948), New Eng. F. Med., 238. 692 . GASKELL, W. H. (1916), 'The Involuntary Nervous System,'

GOLDENBERG, M., SNYDER, C. H., and ARANOW, H. (1947) F. Amer. Med. Ass., 135, 971.

HARTMANN, M., and ISLER, H. (1939), Arch. exper. Path. Pharmak., 192, 141.

HOLTON, P. (1948), communication to Physiological Society, May 22.

HOLTZ, P., and HEISE, R. (1938), Arch. exper. Path. Pharmakol., $191,87$.

HOLTZ, P., and CREDNER, K. (1942), Arch. exper. Path. Pharmakol., 200, 356.

HOLTZ, P., CREDNER, $K_{i}$ and KRONEBERG, (1947), Ibid.. $204,228$.

, P., and CREDNER, K. (1947), Ibid., 204, 244.

LYONS, R. H., MOE, G. K., NFLIGH, R. B., et al. (1947), Amer. $\%$. Med. Sci., 213,315 .

NICKERSON, M., and GOODMAN, L. S. (1947), f. Pharmacol. Exp. Ther., 89, 167.

OKAZAKI, T. (1932), fap. f. Med. Sci., Trans. IV, Pharmacol.

RAYMON' 23 D-HAMET (1925), Compt. rend. Acad. Sci., 180, 2074. RAYMOND-HAMET (I927), Jbid., 185, 610

SLAUGHTER, O. L., BROWN, H. S., and WAKIM, K. G. (1948), Ұ. Lab. Clin. Med., 33, 743 .

STOLI, A. (1920), Verhandl. der Schuceiz. Naturf. Ges., p. 190.

\section{EDITORIAL-(Continued from page 100)}

The first enquiry into the state of Public Health in India was carried out by a Royal Commission in 1859 to investigate the sickness rate amongst troops. As a result Sanitary Commissions were appointed and were the precursors of the present Directors of Public Health. Their work at first was far from smooth amongst communities whose religious pilgrimages have been, throughout history, the starting points of waves of cholera. Yet the great pilgrimage to Mecca has for years now been 'clean.' Primary vaccination is compulsory throughout what was British India, whilst the war against the rat and his flea has checked the devastating plague epidemics. From 1894 institutions were founded for the provision of Pasteur's anti-rabic vaccine; in 1906 a Central Research Institute in Kasauli was soon followed by others in Bombay and Madras whilst in 1921 the Calcutta School of Tropical Medicine with its own hospital enabled clinical teaching to be combined with research into tropical disease. Finally the All-India Institute of Hygiene was established by the generosity of the Rockefeller Foundation for research and for the training of public health workers.

In 1943 the Government appointed a 'Health Survey and Development Committee.' This committee of 25 carried out an exhaustive survey and preșented its report in 1946. Starting from the facts that the death-rate was more than double, the expectation of life at birth less than half and the infant mortality rate more than five times that of New Zealand, it observed that an ill-balanced diet of about $1,75^{\circ}$ calories was typical of the diets of millions, whilst hospital beds available represented 0.24 beds per 1,000 population (England 7.14, United States 10.48 per 1,000).

To remedy this the Committee recommended ' a reasonably comprehensive health cover for the whole population.' It proposed to divide the continent into units of $3,000,000$ population, corresponding closely to the administrative units. Each should eventually be self-supporting in health matters. Each should be subdivided into primary units of 20,000 , representing groups of villages, having a 75-bedded hospital with two medical officers. Thirty such units, representing 600,000 population, should be served by a secondary centre where the work of the primary units is co-ordinated and a 650-bedded hospital provides specialist and laboratory services for the area. At headquarters would be the main teaching and research organization with a hospital of 2,500 beds taking the more complicated cases and those of value for teaching and research, the whole being under the general control of the Minister of Health through the Director of Health Services.

For the Indian medical student, Sir Bennet suggested that teaching should be less didactic, more practical. 'The proper study of mankind is man.'

That Indian medicine will meet this challenge and solve these tremendous problems was Sir Bennet's confident conviction. 